\title{
The night markets of Mellador
}

\section{A taste not to be forgotten. By M. Lee Alexander}

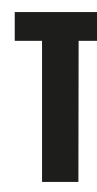

hey say if it's for sale anywhere in the galaxy, you can buy it at the night markets of Mellador. And they're not far wrong. I mean we've got everything. Hundreds of stalls weaving up and down the alleyways of the Old City. Take your pick - precious gems from the mines of Shalanken to spare parts for your spacejet, exotic animals like the giant moths of Chelon, large enough to carry a small child, to Harial golden flutes that play three notes at once. If it's available anywhere within our spinning spiral cluster, you can buy it here.

And I should know. My family's run a tea stall in the market for five generations now. We sell all kinds of tea: some local, some imported from several light years away. Our speciality is Dragon's Flame Tea, brewed from the Thandor leaf. It's hard to harvest, covered with stinging nettles, and harder still to brew, requiring an elaborate recipe to remove the toxins in the tannin. But it's worth it. Just take one sip: so sweet and cool going down, then suddenly you feel like your throat's burst on fire. And just when you think you can't stand another second, the sweet cool taste floods back, any colds or flu you had have melted away, and you feel like you could run straight up a mountain.

It's our most popular item, but there's plenty more types to choose from: green, black, white, red teas, even yellow and purple teas from Philodia. Stop by and try us out. Like all the stalls in the market we're open from the second moonrise to the first dawn. When the first sun crests over the horizon, we close up shop. There are steep fines if you stay open longer, and the authorities are watching us, so we mostly follow the rules. But when our stall is open, I hope it won't sound like boasting to say we have a long queue outside for most of the night.

It's true our place is a bit hard to find, in the way-less-fashionable section of the City, down past the paved streets and into the cobblestone alleys left over from the First Settling. Keep an eye out for the bright red awning, weave your way down the back streets of the Food Lane until you get all the way to the remains of the North Wall to find us. It's out of the way, but prime spots at the market are expensive. We're not wealthy and we can't

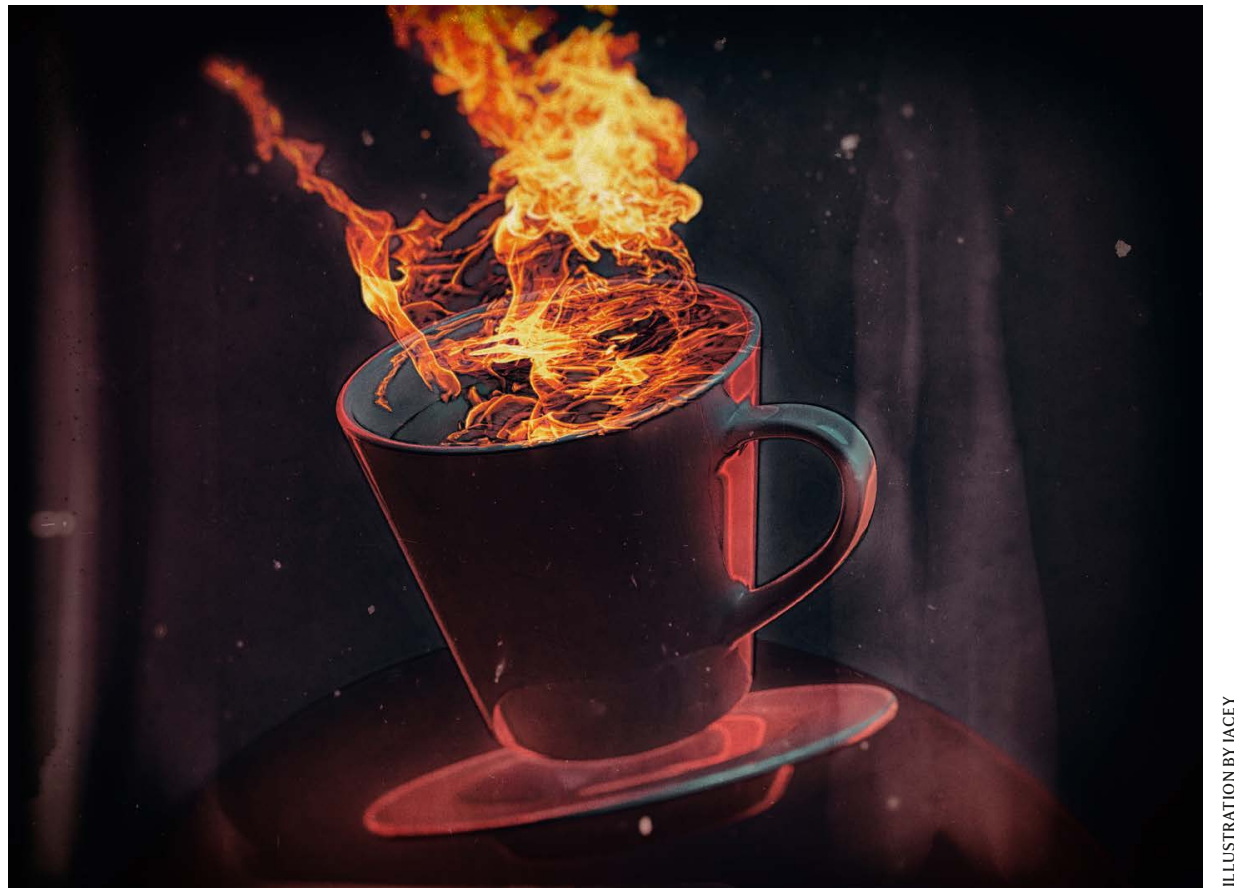

afford the better locations, even after all the years we've been in business, so we take what we can get. We've even had to pitch our tent over a drain in order to find a spot. The Kairne Clan on the other side of the alley make fun of us, their silver Jinpo berries imported from Thelosia glinting in the moonlight. But it's our space, we've had it for years, and we just jeer back have they fixed their mould problem yet, loudly, so their customers can hear.

So please do come on by and see us for the Dragon's Flame Tea, our main speciality. And in addition to our fine selection of teas we do offer one more item, not on the menu, so you have to know to ask for it specially. If you're visiting Mellador from a closed planet, if you're here on a diplomatic visa or official business of some kind and can manage to get away from the handlers who are watching you for just a few minutes (difficult but not impossible in the shoving crowds), or if you're in danger of some kind and can't get out of the City - make your way to our tent and we'll help you escape. You see, there's another reason we pitch our tent over the storm drain. It was secretly converted into a tunnel by my great-great-grandparents and we've been guarding it ever since. We'll give you a canteen of ice-cold water and an erbium-battery torch, and the tunnel path is marked. Just follow it for about two sectors underground and it takes you to close outside the edge of the Dome. You'll emerge into the Outback and from there you're on your own. There are quite a few growing settlements forming there if you just want to disappear, and a crude spaceport with maverick pilots willing to let you hitch a ride to their next port of call. And you're away.

So we can get you out. It'll cost you something, but not much: we're pretty reasonable. It'll have to be cash as you don't want to leave a trail. Don't use your Iris- or Thumb-credits whatever you do - they'll trace right back to you! If you don't have cash we're willing to barter in all kinds of goods: just make us an offer. We're not in it for the money, we believe in what we're doing, and, like I said, it's a family-run business so we try to keep costs low. We'd do it for free but we can't, because we have to pay our suppliers, and the occasional bribe, and the process is not without risk. If we're caught we'll pay the same penalty as you. And none of us is looking for a one-way ticket to the penal colony salt mines 


\section{Futures}

of Haldovar Seven. So we charge just enough to stay in business, and to keep the tunnel and our tea stall open. Because it really is true: if it's for sale anywhere in the galaxy you can buy it in the night markets of Mellador-commodities as rare as Dragon's Flame Tea, or even freedom, if you're willing to pay the price.
M. Lee Alexander's work is inspired by her love of nature, travel and culture. She writes short fiction, poetry and memoirs, and teaches creative writing at William \& Mary in Williamsburg, Virginia. 